
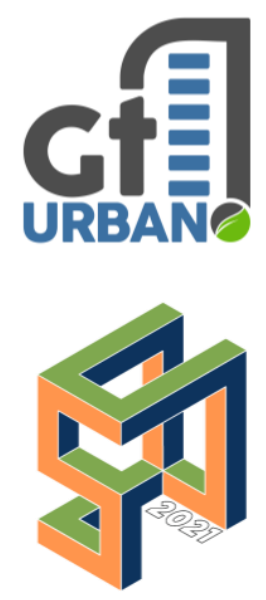

SINGEURB

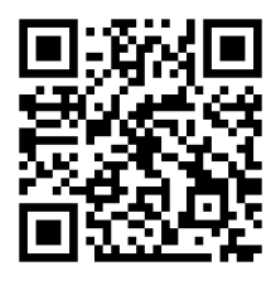

Como citar:

MONTEIRO, Deyvid.

Estatuto da

metrópole e funções

públicas de interesse

comum: O caso da

região metropolitana

de Porto Alegre, RS.

In: III SIMPÓSIO

NACIONAL DE

GESTÃO E

ENGENHARIA

URBANA:

SINGEURB, 2021,

Maceió. Anais...

Porto Alegre:

ANTAC, 2021. p. 1-8.

Disponível em:

https://eventos.antac.

org.br/index.php/sin

geurb/issue/view/14

\title{
Estatuto da metrópole e funções públicas de interesse comum: $O$ caso da região metropolitana de Porto Alegre, RS.
}

\author{
Metropole statute and public functions of \\ common interest: The case of the metropolitan \\ region of Porto Alegre, Rs.
}

Deyvid Monteiro, Universidade Federal do Rio Grande do Sul, deyvidalex@hotmail.com

\section{RESUMO}

O Estatuto da Metrópole determina que as Regiões Metropolitanas brasileiras desenvolvam e aprovem seus Planos de Desenvolvimento Urbano Integrado (PDUI). Dentre os instrumentos, o Estatuto da Metrópole atentou para a importância do compartilhamento das Funções Públicas de Interesse Comum (FPIC). As FPIC são entendidas como serviços urbanos que ultrapassam os limites de um município, causando impactos sobre os demais, como por exemplo, a mobilidade urbana, o saneamento básico, o uso do solo metropolitano e o sistema de informações georreferenciadas. O presente trabalho tem como objetivo principal gerar reflexões com os potenciais agentes envolvidos (Universidades, Secretarias e Fundações Estaduais e Prefeituras Municipais) no processo de construção do Plano de Desenvolvimento Urbano Integrado (PDUI) acerca das funções públicas de interesse comum (FPIC) no contexto da Região Metropolitana de Porto Alegre (RMPA). Para o desenvolvimento deste trabalho foram realizadas 20 reuniões com a presença de 49 técnicos pertencentes à Metroplan, a Fundação de Economia e Estatística (FEE), a Secretaria de Planejamento, Governança e Gestão do Estado (SEPLAN), e a 7 (sete) Prefeituras Municipais pertencentes à Região Metropolitana. Dentre as principais contribuições desta pesquisa está: a identificação dos principais instrumentos presentes no Estatuto da Metrópole, assim como a discussão acerca das FPIC no contexto da RMPA.

Palavras-chave: Funções Públicas de Interesse Comum, Estatuto da Metrópole, Região Metropolitana.

\begin{abstract}
The Metropolis Statute requires the Brazilian Metropolitan Regions to develop and approve their Integrated Urban Development Plans (PDUI in Portuguese). Among the instruments, the Metropolis Statute considered the importance of sharing Public Functions of Interest Common (FPIC Portuguese). The FPIC are understood as urban services that exceed the limits of one municipality, causing impacts on the others, such as urban mobility, basic sanitation, metropolitan land use and the georeferenced information system. The present work
\end{abstract}


has as main objective to generate reflections with the potential agents involved (Universities, Secretariats and State Foundations and Municipal Prefectures) in the process of construction of the Integrated Urban Development Plan (PDUI) about the public functions of common interest in the context of the Metropolitan Region of Porto Alegre (RMPA). Twenty meetings were held with the participation of 49 technicians from Metroplan, the Economics and Statistics Foundation (FEE Portuguese), the Secretariat for Planning, Governance and State Management (SEPLAN Portuguese), and 7 (seven) City Halls Municipalities belonging to the Metropolitan Region. Among the main contributions of this research are: the identification of the main instruments present in the Statute of the Metropolis, as well as the discussion about FPIC in the RMPA context.

Keywords: Common Functions of Public, Interest, Metropolis Statut, Metropolitan Region.

\section{INTRODUÇÃO}

As primeiras Regiões Metropolitanas (RM) brasileiras foram instituídas pelo Governo Federal por meio de duas leis: a Lei Complementar n14, de 8 de junho de 1973 e a Lei complementar $n^{\circ}$ 20, de $1^{\circ}$ de julho de 1974. A Lei ${ }^{\circ} 14 / 73$ estabeleceu as RM de São Paulo, Belo Horizonte, Porto Alegre, Recife, Salvador, Curitiba, Belém e Fortaleza. A Lei $n^{\circ}$ 20/74 unificou os Estados do Rio de janeiro e da Guanabara e estabeleceu a RM do Rio de Janeiro. Uma RM é composta pela sobreposição de inúmeros serviços urbanos, tais como, sistema de transportes, saneamento básico e uso do solo.

Alguns desses serviços urbanos ultrapassam os limites de um município, causando impactos sobre os demais. Nas Regiões Metropolitanas, Funções Públicas de Interesse Comum (FPIC) muitas vezes abrangem populações de mais de uma cidade pertencente a uma RM. Hoje, no Brasil, 104,2 milhões de pessoas vivem em 71 Regiões Metropolitanas. Do mesmo modo como as cidades se tornaram territórios compartilhados por um contingente populacional que se desloca entre um município e outro diariamente, o planejamento e a gestão dos serviços urbanos dessas cidades se tornam mais eficientes quando compartilhados entre municípios e Estados.

Essa é a principal mudança estabelecida pelo Estatuto da Metrópole, promulgado em janeiro de 2015 pela Lei Federal no 13.089/15. De modo geral, essa Lei determina que as Regiões Metropolitanas e conurbações brasileiras desenvolvam e aprovem seus Planos de Desenvolvimento Urbano Integrado (PDUI). Concomitantemente, essa mesma Lei institui o compartilhamento de responsabilidades no planejamento e na execução de ações para o cumprimento das FPIC no âmbito do desenvolvimento urbano integrado.

Essa gestão compartilhada com órgãos, entidades metropolitanas, governos Estaduais e os municípios, tende a permitir a qualificação dos serviços a partir do planejamento urbano integrado. Neste contexto, algumas capitais brasileiras já deram início a esse processo junto às Regiões Metropolitanas (RMs) que compõem. Dentre tais RMs podem ser mencionados os casos de: São Paulo, Rio de Janeiro e Belo Horizonte. Essas RMs construíram seus PDUIs a partir de três modelos distintos: o primeiro caso foi desenvolvido internamente; o segundo caso contou com o apoio de uma consultoria; e no terceiro caso, a agência metropolitana estabeleceu parceira com instituições de ensino para a elaboração do documento.

No caso da RM de Porto Alegre - RMPA, foco deste trabalho, o PDUI tem gerado uma série de discussões com diversos agentes envolvidos (órgãos Estaduais e municipais) responsáveis pelo seu desenvolvimento. A RMPA abrange atualmente 34 municípios, no qual residem aproximadamente 4.282 .410 habitantes. No tocante à gestão metropolitana atual, além das 34 Prefeituras Municipais, atuam na RMPA órgãos e entidades setoriais dos governos Estadual e Federal, cada qual com políticas, prioridades e orçamentos 
próprios. Frente à complexidade da RMPA, o seu planejamento e gestão necessitam de uma visão integrada para o tratamento dos problemas visando à compatibilização de ações das diversas entidades que atuam e influenciam o seu território.

No entanto, em relação aos demais Estados brasileiros, pode-se observar que o processo de construção do PDUI no contexto da RM de Porto Alegre tem sido lento. A frágil conjuntura política e a atual situação econômica do Estado do Rio Grande do Sul (RS) parecem potencializar o enfraquecimento das discussões necessárias à construção da governança interfederativa para elaboração do PDUI. Neste sentido, parte-se do pressuposto que se faz necessário um esforço dos agentes envolvidos na busca da concretização de tais discussões para elaboração do PDUI da RMPA.

A partir do exposto, o presente trabalho tem como objetivo principal gerar reflexões com os potenciais agentes envolvidos (Secretarias, Fundações Estaduais e Prefeituras Municipais) no processo de construção do Plano de Desenvolvimento Urbano Integrado (PDUI) acerca das Funções Públicas de Interesse Comum (FPIC) no contexto da Região Metropolitana de Porto Alegre (RMPA). A fim de alcançar o objetivo principal deste trabalho, foram consideradas para discussão as FPIC de: mobilidade urbana, saneamento básico, e uso do solo metropolitano.

\section{METODOLOGIA}

A RMPA é, atualmente, formada por 34, conforme representado na Figura 1.

Figura 1- Mapa dos municípios pertencentes à RMPA

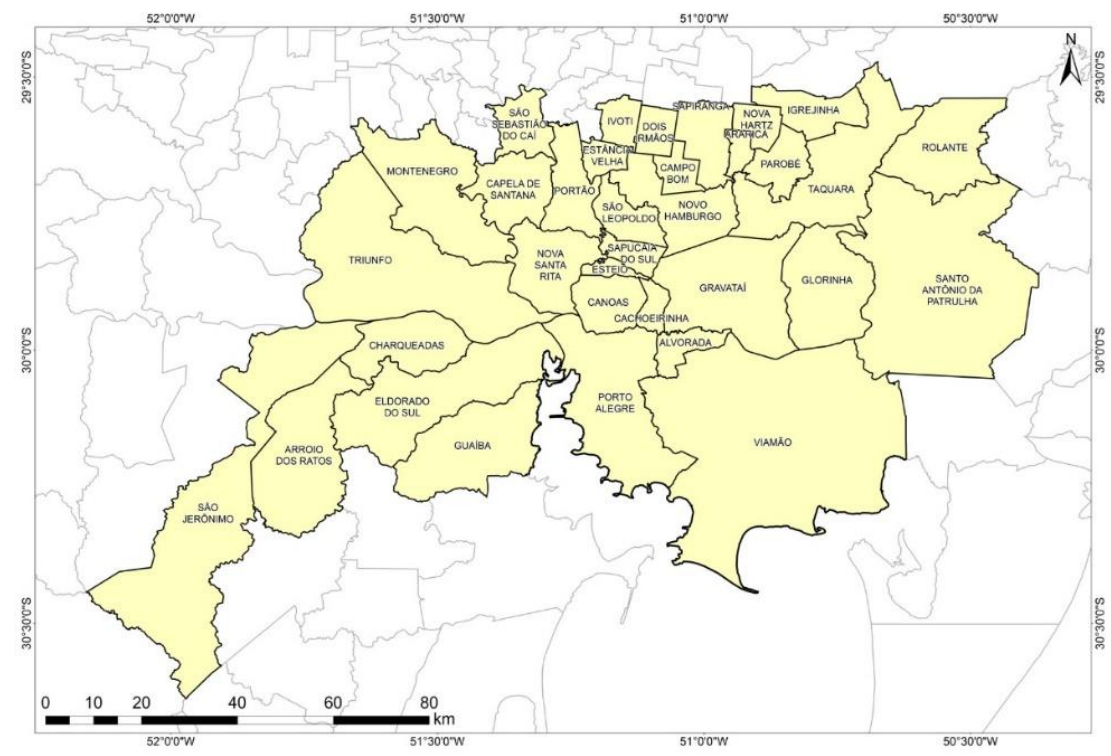

Fonte: Elaboração próprio autor (2018)

O Estatuto da Metrópole fez reascender em 2015 as discussões acerca do PDUI da RMPA. Em função de suas atribuições legais, a METROPLAN ficou responsável pela condução do processo de desenvolvimento do Plano. 
Como procedimentos metodologias para o desenvolvimento desta pesquisa foram realizadas 20 (vinte) reuniões presenciais que visaram gerar discussões acerca dos conteúdos elencados ao PDUI no contexto da RMPA.

A técnica de pesquisa utilizada para condução dessas reuniões foi o Grupo Focal, com 10 (dez) técnicos e pesquisadores da METROPLAN e 49 (quarenta e nove) técnicos pertencentes: à Fundação de Economia e Estatística - FEE, à Secretaria de Planejamento, Governança e Gestão do Estado- SEPLAN, e a Prefeituras Municipais da RMPA.

Para a técnica do grupo focal, a equipe de técnicos da METROPLAN procurou seguir as diretrizes propostas por Ressel et al. (2008). A equipe de pesquisa foi composta por três pessoas, sendo uma do moderador do grupo (que conduziu a conversa) e as outras duas colaboradoras. Os colaboradores trabalharam principalmente na observação e registro dos dados (que foram anotados e registrados, com a autorização dos participantes). A discussão foi organizada em torno dos tópicos delimitados nesta pesquisa (mobilidade urbana, saneamento básico e uso do solo metropolitano), conforme apresentado na sequência.

\section{RESULTADOS E DISCUSSÕES}

\subsection{Funções públicas de interesse comum (FPIC) no contexto da região metropolitana de porto alegre (rmpa)}

A partir das reuniões realizadas com os principais agentes envolvidos foi possível discutir e aprofundar o conhecimento acerca das FPIC no contexto da RMPA. As FPIC de mobilidade urbana, saneamento básico e uso do solo metropolitano.

\subsubsection{Mobilidade urbana; saneamento básico e uso do solo metropolitano}

A mobilidade urbana abrange o modo e as condições de deslocamento das pessoas e cargas no território urbanizado (PEDROSO E NETO, 2015). Diversos fatores podem afetar a demanda e o perfil das viagens entre municípios vizinhos, tais como: alterações no uso do solo, a oferta de modais e linhas de transporte público, infraestrutura viária (pavimentação, corredores de ônibus, ciclovias, faixas exclusivas, entre outros), mobiliário e equipamentos públicos de transporte (terminais, estações, paradas, entre outros), oferta de empregos, vagas de ensino, dentre outros.

No caso da RMPA, segundo dados do IBGE (CENSO 2010), cerca de 500 mil pessoas se deslocam diariamente para estudar e/ou trabalhar em outro município da RMPA, onde Porto Alegre é o principal destino. Viamão, Alvorada e Canoas são os municípios que mais originam as viagens pendulares. Percebese também um grande fluxo de pessoas entre os municípios ao norte da RMPA, onde Novo Hamburgo se destaca como principal destino dos deslocamentos originados de Campo Bom, Dois Irmãos, Estância Velha, Ivoti, São Leopoldo e Sapiranga, principalmente.

Contudo, o fluxo de pessoas no sistema de transporte público entre os municípios não é feito de forma integrada. A falta de integração na gestão do transporte público é um dos maiores problemas da mobilidade em Regiões Metropolitanas, pois apesar dos municípios compartilharem cotidianamente os fluxos de mercadorias e pessoas, em geral, não atuam da mesma forma nas soluções para as questões regulatórias e financeiras das políticas de investimento, de planejamento e de gerenciamento. 
A criação de entidade multifederativa, geralmente denominados de consórcios públicos, seria uma maneira para lidar com os conflitos da falta de integração numa RM. Contudo, há poucas experiências nesse formato no país pois é difícil equacionar a distribuição de receitas e subsídios em sistemas integrados e solucionar questões de autonomia e titularidade dos municípios nos serviços de transporte público. Na RMPA, há indicação no PITMUrb, porém ainda não se conseguiu implementá-lo.

A infraestrutura também é um elemento essencial para a eficiência e qualidade do transporte. Assim como é importante ter um bom planejamento operacional, o qual defina itinerários, integrações, frequências e tabelas horárias de acordo com a demanda, é imprescindível uma infraestrutura compatível e integrada entre os municípios da RM. Os terminais, faixas exclusivas, corredores de ônibus, linhas de trem e metrô, sistemas de VLTs e/ou BRTs, ciclovias, por exemplo, podem melhorar o desempenho do transporte público se estiverem bem planejadas e integradas entre si e adequadas com a situação urbana encontrada.

No caso do transporte público, a integração entre os sistemas urbanos e metropolitanos racionaliza a rede de transporte como um todo, proporcionando a otimização da infraestrutura utilizada e a redução da sobreposição de linhas pela integração tarifária intra e intermodal. Desta maneira, por exemplo, seria permitido a utilização de uma linha metropolitana por usuários urbanos. Essa integração dos sistemas poderá repercutir: na diminuição da frota; diminuição dos congestionamentos nos corredores e faixas exclusivas; e aumento da frequência de linhas com mesmo destino, contribuindo para uma mobilidade eficiente e qualificada, como é almejada pelo Plano Nacional de Mobilidade Urbana (LEI FEDERAL no 12.587).

Em síntese a gestão integrada dos modos, serviços e da infraestrutura abrangida pelo sistema de mobilidade urbana é a forma mais indicada para alcançar a eficiência e qualidade do transporte. Dentre as ações relativas à FPIC de Mobilidade Urbana identificadas no âmbito da RMPA estão: Integração entre os diversos Modais; Plano e diretrizes viárias; Plano Ferroviário - Trens e Metros; Plano Hidroviário; Plano Cicloviário; Tráfego e infraestrutura das redes de vias arteriais e coletoras que exerçam a ligação entre os municípios.

A Lei Federal n 11.445, de 05 de janeiro de 2007 estabelece o saneamento básico como um conjunto de serviços, infraestrutura e instalações operacionais de: abastecimento de água potável; esgotamento sanitário; limpeza urbana; manejo de resíduos sólidos; e drenagem e manejo de águas pluviais urbanas (art. $3^{\circ}$, inciso I, da Lei $n^{\mathrm{o}}$ 11.445).

A abordagem da FPIC de saneamento básico em nível metropolitano é fundamental, uma vez que além da prestação dos serviços envolverem investimentos vultosos, o fornecimento de água inadequado ou o despejo de esgoto ou o destino final de resíduos sólidos realizado de forma irregular por um Município também afetará os demais integrantes daquela região, ou seja, não é um sistema de saneamento básico isolado, mas sim integrado.

Em síntese, como se pode notar há um interesse comum que permeia os membros de uma RM em receber os serviços de saneamento básico com eficácia e qualidade. Para que isso aconteça se faz necessária uma integração entre os Municípios, Município-Mãe e Estado-membro, com o fim de viabilizar a organização, execução e planejamento desta FPIC.

A FPIC Uso do solo metropolitano, que poderia ser melhor designada como Ordenamento Territorial, compreende a estrutura espacial metropolitana em termos de estrutura viária, distribuição espacial de atividades e fluxos. É uma função estreitamente relacionada e que condiciona a mobilidade urbana. Fora 
do âmbito técnico do urbanismo e do planejamento urbano e regional, raramente é reconhecida como de relevância e interesse regional.

O disciplinamento do uso do solo em âmbito regional (metropolitano) entra em conflito com o municipalismo exacerbado, que ocorre no Rio Grande do Sul. Raros gestores reconhecem a dimensão e a influência do uso do solo além dos limites municipais. O tema ficou ainda mais difícil de ser abordado depois da Constituição Federal de 1988, que atribuiu ao município competência para legislar sobre uso e parcelamento do solo (Art. 30). O diploma legal não reconhece a conveniência de um tratamento diferenciado em municípios integrantes de Regiões Metropolitanas.

O PDM da RMPA, elaborado em 1973 previu que sua proposta espacial fosse implementada por meio dos planos diretores (PDM) a serem elaborados para os 14 municípios que compunham na época a RMPA. Esta estratégia não considerou os conflitos de interesse sempre presentes na discussão, aprovação e aplicação dos planos diretores.

Outra previsão do PDM de 1973 foi que a visão técnica metropolitana influísse diretamente na escolha de glebas para os grandes programas habitacionais implantados no país até a extinção do Banco Nacional de Habitação (BNH), no final dos anos 80. De fato, o Estado, por meio da METROPLAN, participou da escolha de alternativas de localização, mas frequentemente preponderaram outros critérios.

Para complementar o PDM, nos anos seguintes foram elaborados outros planos setoriais e estudos. Entre esses estudos, se destaca pelo pioneirismo, no campo do uso do solo, o Estudo da destinação do solo rural na RMPA em 1976. Foram analisadas áreas sem previsão de urbanização, considerando seu potencial agrícola, seu potencial mineral entre outros critérios, para garantir simultaneamente o desenvolvimento do potencial econômico dessas áreas não urbanas da Região e a contenção da expansão urbana. Esse reconhecimento da necessidade de tratar do urbano e do rural em conjunto apareceu pela primeira vez na Legislação Federal de 1988.

A partir de 1977 a METROPLAN começou a se manifestar sobre o descadastramento de imóveis rurais no INCRA e sobre projetos de parcelamento do solo urbano, com base em convênios com os municípios. Esta atividade se fortaleceu após a aprovação da Lei Federal 6.766/79, que instituiu o Termo de Anuência Prévia nas RMs. O Termo de Anuência Prévia é um instrumento de acompanhamento e qualificação da expansão das cidades por meio da urbanização de novos espaços territoriais. $\mathrm{O}$ instrumento não permite conter a expansão horizontal quando está se revela inconveniente, já que a delimitação do perímetro urbano é uma prerrogativa municipal exercida frequentemente sem fundamentação técnica.

A Lei Estadual de Desenvolvimento Urbano 10.116/94 define critérios para verificação da necessidade de expansão dos perímetros urbanos, mas este conteúdo não tem sido aplicado, nem exigido. A Lei não contém qualquer mecanismo que preveja a exposição e discussão dos conflitos de interesse envolvidos. Desde meados dos anos 80, a crise do planejamento normativo impositivo se instalou no órgão metropolitano de Porto Alegre. O caminho escolhido foi substituir o plano por conjuntos de critérios que, aplicados a cada projeto, revelariam sua pertinência e adequação, ou não. Apesar de algumas tentativas, a RMPA nunca mais teve um plano regional abrangente.

O Estatuto da Metrópole, de janeiro de 2015, trouxe para as RMs a obrigação de ter plano com forte caráter territorial. No Parágrafo $1^{\circ}$, do Artigo 12, constam como conteúdos mínimos do plano: macrozoneamento da unidade territorial urbana, diretrizes quanto à articulação dos Municípios no parcelamento, uso e 
ocupação do solo urbano, e delimitação de áreas com restrições à urbanização visando à proteção do patrimônio ambiental ou cultural, bem como das áreas sujeitas a controle especial pelo risco de desastres naturais, se existirem.

Em síntese, tais conteúdos se tornam relevantes para o ordenamento territorial da região e requerem ampla discussão com a sociedade civil e decisão política que os respalde. Um dos desafios do planejamento metropolitano reside em estabelecer fóruns de comunicação e discussão em que se revelem os significados dos incentivos e restrições urbanísticas.

\section{CONSIDERAÇÕES FINAIS}

O presente artigo teve como objetivo principal gerar reflexões com os potenciais agentes envolvidos (Universidades, Secretarias e Fundações Estaduais e Prefeituras Municipais) no processo de construção do Plano de Desenvolvimento Urbano Integrado (PDUI) acerca das Funções Públicas de Interesse Comum (FPIC) no contexto da Região Metropolitana de Porto Alegre (RMPA). Dentre as principais contribuições desta pesquisa estão: a identificação dos principais instrumentos presentes no Estatuto da Metrópole, a discussão acerca das FPIC no contexto da RMPA.

De modo geral, foi visto que o processo de discussão é complexo e que demanda uma extensa e qualificada equipe técnica. A fim de alcançar o objetivo principal deste trabalho, foi realizada, inicialmente, uma síntese dos principais instrumentos presentes do Estatuto da Metrópole. O principal ponto evidenciado no Estatuto da Metrópole para construção do Plano foi a necessidade de uma Governança Interfederativa a ser promovido pelos Governos Estaduais e os Municípios envolvidos, objetivando organizar, planejar e executar as Funções Públicas de Interesse Comum.

No âmbito da RMPA foram discutidas no presente documento as Funções Públicas de Interesse Comum de: mobilidade urbana, saneamento básico e uso do solo metropolitano. No tocante a mobilidade urbana foi discutida a necessidade a gestão integrada dos modos, serviços e da infraestrutura abrangida pelo sistema de mobilidade urbana. Quando ao saneamento foi apontado a necessidade de integração entre os Municípios com o fim de viabilizar a organização, execução e planejamento desta função pública. No que se refere ao uso do solo metropolitano e fica evidente a necessidade de engajamento da população na busca de soluções mais adequadas para as cidades.

O resultado da implantação do PDUI são oportunidades expressivas para as Regiões Metropolitanas, incluindo a priorização de investimentos metropolitanos, a ampliação e a integração de infraestruturas, a integração da economia metropolitana e o desenvolvimento social e sustentável a partir da gestão integrada dos serviços. O processo de construção e implantação, particularmente, do PDUI na RMPA representa um desafio adicional em face da atual inexistência de um planejamento urbano que considere o território e os serviços urbanos de forma integrada, conforme discutido nas FPIC.

Uma vez construídos em consonância com as diretrizes já estipuladas pelos planos diretores, os PDUIs têm o potencial de mudar o modo como as cidades são planejadas e, consequentemente, a dinâmica dos deslocamentos e do dia a dia das pessoas. Ao instituir os mecanismos que permitem ou levam à criação de novas centralidades, redução da necessidade de deslocamentos, mudanças no uso do solo e nas divisões de responsabilidades, esses planos tendem a qualificar substancialmente o desenvolvimento urbano, tornando as cidades mais sustentáveis para promover a qualidade de vida da população. 


\section{REFERÊNCIAS}

BRASIL. Lei no 13.089, de 12 de janeiro de 2015. Institui o Estatuto da Metrópole, altera a Lei no 10.257, de 10 de julho de 2001, e dá outras providências. Diário Oficial da União, Atos do Poder Legislativo, Brasília, DF, 13 jan. Seção 1, p. 2. 2015.

BRASIL. Lei 6.766, de 19 de dezembro de 1979. Dispõe sobre o Parcelamento do Solo Urbano e dá outras Providências. República Federativa do Brasil, Poder Executivo, Brasília, DF. 1979.

BRASIL. Lei Estadual 10.116, de 23 de março de 1994. Institui a Lei do Desenvolvimento Urbano, que dispõe sobre os critérios e requisitos mínimos para a definição e delimitação de áreas urbanas e de expansão urbana, sobre as diretrizes e normas gerais de parcelamento do solo para fins urbanos, sobre a elaboração de planos e de diretrizes gerais de ocupação do território pelos municípios e dá outras providências. 1994.

PEDROSO, F. F. F.; NETO, V. C. L. Transportes e Metrópoles: aspectos da integração em regiões metropolitanas. Textos para Discussão 2113, Rio de janeiro, IPEA. 2015.

RESSEL L, BECK C., GUALDA D, HOFFMANN I., SILVA R., SEHNEM G., "O uso do grupo focal em pesquisa qualitativa", Texto and Contexto Enfermagem, 2008. 